\title{
Influence of Physician's Lifestyle on the \\ Prescription of Healthy Habits to Breast Cancer Patients (LACOG 1218)
}

Renata Costa Cangussú ( $\square$ rcangussu1977@gmail.com )

Rede D'Or São Luiz: Rede D'Or Sao Luiz https://orcid.org/0000-0001-7514-9342

Eldsamira Mascarenhas

Rede D'Or: Rede D'Or Sao Luiz

Taiane Francieli Rebelatto

Latin American Cooperative Oncology Group

Facundo Zaffaroni

Latin American Cooperative Oncology Group

Rafaela Gomes de Jesus

Latin American Cooperative Oncology Group

Paulo Ricardo Nunes Filho

Latin American Cooperative Oncology Group

Gustavo Werutsky

Latin American Cooperative Oncology Group

\section{Research Article}

Keywords: breast cancer, healthy habits, physician`s lifestyle

Posted Date: October 21st, 2021

DOl: https://doi.org/10.21203/rs.3.rs-840168/v1

License: (a) This work is licensed under a Creative Commons Attribution 4.0 International License.

Read Full License 


\section{Abstract}

\section{BACKGROUND}

Healthy lifestyle is capable of positively modifying the survival of breast cancer(BC) patients. We aimed to evaluate how physician's lifestyle influences on the prescription of healthy habits to $B C$ patients.

\section{METHODS}

An online questionnaire to evaluate physician lifestyle and prescription of healthy habits to $B C$ patients was developed and circulated by e-mail to physicians dedicated to treat BC patients. A multivariate Poisson regression analysis assessed which factors of physician lifestyle could influence on prescription of healthy habits.

\section{RESULTS}

A total of 267 physicians answered the questionnaire from October to November 2018. In terms of physician lifestyle, $228(85.4 \%)$ had healthy eating habits and $236(88.4 \%)$ practiced physical activity. Overall, $84.3 \%$ of the physicians advised their BC patients on the importance of lifestyle modification. Physicians who did not exercise regularly have a higher chance of not advising for health lifestyle (RR $2.48 ; p=0.0265)$ as opposite to physicians $\geq 50$ years-old (RR $0.37 ; p=0.0118)$. Obesity treatment and management was performed by $45.3 \%$ of physicians. Being a breast surgeon (RR $1.29 ; p=0.0025$ ) or radiation oncologists (RR 1.82; $\mathrm{p}=0.0025)$ were associated with not performing obesity treatment and management. About $53.4 \%$ of physicians referred overweight or obese patients to a dietitian and/or endocrinologist. Male gender ( $R R$ 1.35; $p=0.0296)$, breast surgeons (RR 1.99; $p=0.0001$ ) and clinical practice in public health system $(R R 1.53 ; p=0.0012)$ were associated with not referring as opposed to physicians $\geq 50$ years-old (RR $0.46 ; p=0.0005)$.

\section{CONCLUSION}

In general physicians treating $\mathrm{BC}$ patients have a healthy lifestyle. Only half of $\mathrm{BC}$ patients' physicians treat obesity or refer these patients to specialist which in this case may impact BC patient's outcome.

\section{Novelty \& Impact Statements}

A healthy lifestyle has been shown to have a positive impact on the quality of life, risk of recurrence, and overall survival in breast cancer. Physicians play an important role in encouraging their patients to lifestyle modification. LACOG 1218 survey identified that physicians treating BC patients have a healthy lifestyle and physician`s lifestyle influences on the prescription of healthy habits to BC patients. Thus, strategies to engage physicians in healthier behaviors should be developed.

\section{Introduction}


Breast cancer (BC) is the most frequent cancer diagnosed in women worldwide. In 2018, 2,088,849 new cases and 626,679 deaths due to BC were expected. (1) In addition to the advances in pharmacological therapies that have improved overall survival (OS) in the last decades, a healthy lifestyle has also been shown to have a positive impact on both quality of life and OS in breast cancer patients. $(2,3)$

The World Health Organization (WHO) defines a healthy lifestyle as a combination of healthy eating, regular physical activity, and avoidance of tobacco and harmful alcohol consumption. (4) Clinical benefits have been observed in studies with BC patients who follow a healthy lifestyle. $(3,5)$ According to the Women's Intervention Nutrition Study, dietary fat reduction compared to usual diet may improve relapse-free survival of $\mathrm{BC}$ patients (hazard ratio [HR] 0.76, 95\% Cl 0.60-0.98). (6) A subsequent randomized clinical trial from the Women's Health Initiative concluded that BC patients who reduced fat intake to $20 \%$ and increased fruit, vegetable, and grain intake also had improvement in OS (HR 0.78, $95 \% \mathrm{Cl}, 0.65-0.94)$. (7) The regular practice of physical activity, defined as at least 150 minutes of moderate-intensity, or 75 mins of vigorous-intensity, aerobic physical activity per week (8), has not only helped to maintain adequate weight, but also shown to reduce mortality in up to $46 \%$ and BC mortality in up to $33 \%$ among BC survivors. $(9,10)$

Physicians play a critical role in encouraging their patients to change their habits. Further, recent data suggest that the success in promoting healthy lifestyle in patients is strongly correlated to the physician's own habits. (11) Physicians with less healthy habits tend to be less proactive in giving advice or motivating practices that they themselves do not follow.(12-14) However, this relation has not been established among physicians caring for BC patients.

Therefore, we developed a survey to evaluate physician`s lifestyle and its influence on the prescription of healthy habits to $\mathrm{BC}$ patients.

\section{Materials And Methods}

An online questionnaire composed by 14 objective questions was developed with the goal to evaluate physician lifestyle and prescription of healthy practices to $\mathrm{BC}$ patients. The first questions addressed the following domains of physician lifestyle: diet, physical activity, smoking, weight, amount of sleep, and alcohol consumption (using the Modified Version of Quantity-Frequency index). Other questions addressed the prescription of healthy habits to patients, the management of obesity and the frequency of referral to an endocrinologist or dietitian in case of overweight or obesity. The estimated time to answer the questionnaire was 5 minutes. The full questionnaire is presented in Supplementary Material Table S1.

A brief explanation of the study proposal containing the survey link was sent by e-mail to members of the Brazilian Society of Clinical Oncology (SBOC) and Latin American Cooperative Oncology Group (LACOG). The study population consisted of clinical oncologists, breast surgeons and radiation oncologists involved in the treatment of $\mathrm{BC}$ patients. No financial incentive was offered to encourage completion of the survey. The definition of healthy lifestyle follows the WHO recommendations: healthy diet (eating lots of fruits and vegetables, reducing fat, sugar, and salt intake), physical activity (at least 150 minutes of 
moderate-intensity, or 75 mins of vigorous-intensity, aerobic physical activity, per week), no smoking, and BMl between $18.5-24.9 \mathrm{~kg} / \mathrm{m}^{2}$.

The primary outcome was to evaluate the correlation between the physician`s lifestyle and the prescription of healthy habits to $\mathrm{BC}$ patients. We also described the demographic characteristics and lifestyle of these physicians and identified characteristics that could influence prescription of healthy habits, patient weight management, and endocrinologist or dietitian referral.

\section{Statistical Analysis}

Answers to the 14 items of the questionnaire were summarized by absolute and relative frequencies. A multivariate Poisson regression analysis with robust variance was adjusted to assess which factors of physician lifestyle could influence prescription. All analyses were performed using SAS statistical software (version 9.4; SAS Institute, Inc. Cary, NC). A significance level of 5\% was considered.

\section{Results}

From October 2018 to November 2018, 267 physicians answered the questionnaire. Of these, 142 (53.2\%) were clinical oncologists, 116 (43.5\%) were breast surgeons, and 9 (3.4\%) were radiation oncologists. Ninety $(33.7 \%)$ had clinical practice exclusively in private health care, 101 (37.8\%) worked mostly in the private sector, 60 (22.5\%) worked mostly in the public Brazilian health care system, and only $16(6 \%)$ worked exclusively in the public health care system. The majority were female (58.4\%), $49.1 \%$ were between the ages of 30 and $39,30.7 \%$ were between the ages of 40 and 49 and $20.2 \%$ had more than 50 years.

Descriptive analysis of physicians' habits is shown in Table 1. A total of $228(85.4 \%)$ physicians followed the guidelines on diet most of the time, whereas $236(88.4 \%)$ practice physical activity. Alcohol consumption was moderate among physicians and only $8(3 \%)$ of them were current smoker. Overweight and obesity were found in $93(34.9 \%)$ of the interviewees and $163(61.1 \%)$ had BMI between the recommended level of 18.5-24.9. Most of the physicians (79.4\%) sleep between 5 and 7 hours per day, and $44(16.5 \%)$ sleep more than 7 hours per day. Of all participants only $23(8.6 \%)$ physicians followed all the evaluated lifestyle recommendations on diet, physical activity, smoke habits, alcohol consumption and amount of sleep, and had an ideal BMI. 
Descriptive analysis of physicians' habits

Information n (\%)

Do you personally follow the recommendations of eating habits?

Yes $^{1}$

$\mathrm{No}^{2}$

Do you personally practice physical activity?

Yes $^{3}$

$\mathrm{No}^{4}$

Do you consume alcohol?

No

Yes ${ }^{5}$

$212(79.4)$

\section{Do you smoke?}

Yes

No

$259(97.0)$

Average sleep time per day

$<5$ hours

Between 5-7 hours

$212(79.4)$

$>7$ hours

$44(16.5)$

\section{What is your BMI?}

$<25 \mathrm{Kg} / \mathrm{m}^{2}$

$\geq 25 \mathrm{Kg} / \mathrm{m}^{2}$ 93(34.9)

n: number of patients; \%: percent of frequency.

${ }^{1}$ Yes includes the following answers: Yes, all the time. Yes, only occasional deviation. Yes, on weekdays.

${ }^{2}$ No includes the following answers: No, because I usually fail. No because I do not believe it is so important.

${ }^{3}$ Yes includes the following answers: Yes, daily. Yes, the recommended $150 \mathrm{~min} /$ week. Yes, between 50-150min/week. Yes, <50 min/week.

${ }^{4}$ No includes the following answers: No, because I do not have time. Not due to clinical limitations. 
${ }^{5}$ Yes, I drink less than once a month and do not consume 5 or more doses. Yes, I drink 1 or 3 times a month, and may or may not consume 5 or more doses on this occasion(s). I consume 5 or more doses at least once a year and may or may not reach this consumption once a week. Yes, I consume 5 or more doses of alcohol 1 or more times per week.

Overall, $84.3 \%$ of the physicians advised their BC patients on the importance of lifestyle modification. In a multivariate analysis, physicians who did not exercise regularly have a higher risk of not advising healthy lifestyle (relative risk (RR) $2.48 ; 95 \% \mathrm{Cl} 1.28$ to $4.82, \mathrm{p}=0.0265$ ). In turn, being older than 49 years reduced the risk of not advising healthy lifestyle (RR $0.37 ; \mathrm{Cl} 95 \% 0.15-0.92 ; \mathrm{p}=0.0118)$. (Table 2 ) 
Table 2

Physicians characteristics and advice on the importance of lifestyle modification for BC patients Multivariate analysis

Physicians characteristics

Gender

Age(years)

Do not advice about healthy lifestyle (\%)

\begin{tabular}{llll} 
Female & $21(13.5)$ & 1.00 & \\
\hline Male & $21(18.9)$ & 1.71 & $0.90-3.22$
\end{tabular}

$\begin{array}{ll}95 \% & p- \\ \text { confidence } \\ \text { interval }\end{array} \quad \begin{aligned} & \text { value } \\ & \end{aligned}$

0.1113

\subsection{8}

$\begin{array}{llll}30-49 & 37(17.4) & 1.00 & \\ \geq 50 & 5(9.3) & 0.37 & 0.15-0.92\end{array}$

Specialty

\begin{tabular}{llll}
$\begin{array}{l}\text { Clinical } \\
\text { oncologist }\end{array}$ & $17(12.0)$ & 1.00 & \\
\hline Breast surgeon & $22(19.0)$ & 1.87 & $1.04-3.37$ \\
\hline $\begin{array}{l}\text { Radiation } \\
\text { oncologist }\end{array}$ & $3(33.3)$ & 1.92 & $0.69-5.34$ \\
\hline
\end{tabular}

Clinical practice

\begin{tabular}{lccc}
$\begin{array}{l}\text { Exclusively / } \\
\text { Greater mostly } \\
\text { private service }\end{array}$ & $29(15.2)$ & 1.00 & \\
$\begin{array}{l}\text { Exclusively / } \\
\text { Greater mostly } \\
\text { public service }\end{array}$ & $13(17.1)$ & 1.39 & $0.75-2.55$ \\
\hline
\end{tabular}

Do you treat breast cancer?

$\begin{array}{llll}\text { Yes } & 38(14.6) & 1.00 & \\ \text { No } & 4(57.1) & 4.83 & 2.03- \\ & & & 11.05\end{array}$

Do you personally follow the recommendations of eating habits?

\begin{tabular}{lllll|} 
Yes & $32(14.0)$ & 1.00 & \\
\hline No & $10(25.6)$ & 1.36 & $0.71-2.61$
\end{tabular}


physical activity?

\begin{tabular}{|llllll|}
\hline & Yes & $31(13.1)$ & 1.00 & & \\
\hline & No & $11(35.5)$ & 2.48 & $1.28-4.82$ & \\
\hline Do you consume alcohol? & & & & & \\
& Yes & $35(16.5)$ & 1.00 & & \\
\hline & No & $7(12.7)$ & 0.81 & $0.40-1.61$ & \\
\hline Do you smoke? & & & & & 0.6231 \\
\hline & Yes & $2(25.0)$ & 1.00 & & 0.4931 \\
\hline $\begin{array}{l}\text { Average sleep time per } \\
\text { day }\end{array}$ & No & $40(15.4)$ & 0.77 & $0.31-1.90$ & \\
\hline & $<5 h$ & & & & \\
\hline & Between $5-7 h$ & $33(15.6)$ & 0.60 & $0.18-2.01$ & \\
\hline & $>7 h$ & $6(13.6)$ & 0.49 & $0.20-1.21$ & \\
\hline What is your BMI? & & & & & 0.6947 \\
\hline & $<25$ & $25(14.4)$ & 1.00 & & \\
\hline
\end{tabular}

Regarding obesity management, 121 (45.3\%) physicians did some type of obesity management, 120 $(44.9 \%)$ did not manage obesity because they did not feel properly trained to do that, and $26(9.8 \%)$ did not manage obesity for other reasons. In multivariate analysis, physicians who did not follow healthy eating habits most of the time (all the time, only occasional deviation, and on weekdays) did not have an increasing in the risk of not manage obesity ( $R R 1.28 ; 95 \% \mathrm{Cl} 0.98$ to $1.67, \mathrm{p}=0.0884$ ) Medical specialty influenced obesity management $(p=0.0025)$. Clinical oncologists more frequently managed obesity, while breast surgeons (RR 1.29; $95 \% \mathrm{Cl} 1.02$ to 1.63 ) and radiation oncologists not (RR1.82; $95 \% \mathrm{Cl} 1.43$ to 2.31) (Table 3). 
Table 3

Physicians characteristics and advise on obesity management for BC patients

Multivariate analysis

Physicians

characteristics
Do not perform obesity management

(\%)
Relative Risk

$95 \%$ confidence value interval

Gender

Female
Male

$82(52.6)$

1.00

64 (57.7)

1.07

$0.85-$

1.36

Age (ears)

0.2929

$\begin{array}{llll}30-49 & 118(55.4) & 1.00 & \\ \geq 50 & 28(51.8) & 0.86 & 0.63- \\ & & & 1.16\end{array}$

Specialty

0.0025

$\begin{array}{llll}\text { Clinical oncologist } & 68(47.9) & 1.00 & \\ \text { Breast surgeon } & 69(59.5) & 1.29 & 1.02- \\ & & & 1.63 \\ \begin{array}{l}\text { Radiation } \\ \text { oncologist }\end{array} & 9(100.0) & 1.82 & 1.43- \\ & & & 2.31\end{array}$

Clinical practice

0.6059

Exclusively /

Greater mostly

private service

Exclusively/Greater 38 (50.0) time in public

service

1.00

$108(56.5)$

0.6059

service

Do you treat breast cancer?

$\begin{array}{llll}\text { Yes } & 141(54.2) & 1.00 & \\ \text { No } & 5(71.4) & 1.32 & 0.85- \\ & & & 2.05\end{array}$

Do you personally follow the recommendations of eating habits? 


$\begin{array}{llll}28(71.8) & 1.28 & 0.98- \\ & & & 1.67\end{array}$

Do you personally practice physical activity?

\begin{tabular}{|c|c|c|c|c|c|}
\hline & Yes & $125(53.0)$ & 1.00 & & \\
\hline & No & $21(67.7)$ & 1.05 & $\begin{array}{l}0.77- \\
1.42\end{array}$ & \\
\hline \multirow{3}{*}{$\begin{array}{l}\text { Do you consume } \\
\text { alcohol? }\end{array}$} & & & & & 0.0777 \\
\hline & Yes & $111(52.4)$ & 1.00 & & \\
\hline & No & $35(63.4)$ & 1.26 & $\begin{array}{l}0.99- \\
1.60\end{array}$ & \\
\hline \multirow[t]{3}{*}{ Do you smoke? } & & & & & 0.9528 \\
\hline & Yes & $5(62.5)$ & 1.00 & & \\
\hline & No & $141(54.4)$ & 0.98 & $\begin{array}{l}0.58- \\
1.68\end{array}$ & \\
\hline \multirow[t]{4}{*}{$\begin{array}{l}\text { Average sleep time per } \\
\text { day }\end{array}$} & & & & & 0.4163 \\
\hline & $<5 h$ & $6(54.5)$ & 1.00 & & \\
\hline & Between $5-7 \mathrm{~h}$ & $122(57.5)$ & 1.02 & $\begin{array}{l}0.62- \\
1.68\end{array}$ & \\
\hline & $>7 \mathrm{~h}$ & $18(40.9)$ & 0.80 & $\begin{array}{l}0.44- \\
1.47\end{array}$ & \\
\hline \multirow[t]{3}{*}{ What is your BMI? } & & & & & 0.2516 \\
\hline & $<25$ & $89(51.1)$ & 1.00 & & \\
\hline & $\geq 25$ & $57(61.3)$ & 1.14 & $\begin{array}{l}0.91- \\
1.43\end{array}$ & \\
\hline
\end{tabular}

Do you consume alcohol?

Considering referral, $53.4 \%$ of the overweight or obese patients were referred to a dietitian and/or endocrinologist (Table 4). After multivariate analysis, the following independent factors were associated with not referring patients to a dietitian and/or endocrinologist: male sex (RR 1.35; Cl 95\% 1.03 to 1.76; $\mathrm{p}$ $=0.0296$ ), breast surgeons ( $R R 1.99 ; \mathrm{Cl} 95 \% 1.50$ to $2.64 ; \mathrm{p}<.0001)$ and clinical practice exclusively or most of the time in public health care system (RR 1.53; Cl 95\% 1.20 to 1.96; $p=0.0012$ ). In contrary, physicians older than 49 years had lower risk of not referring overweight or obese patients to a dietitian and/or endocrinologist (RR 0.46; Cl 95\% 0.28 to $0.75 ; p=0.0005$ ). 
Table 4

Physicians characteristics and reference to dietitian or endocrinologist on obesity management for BC patients

\begin{tabular}{|c|c|c|c|c|c|}
\hline \multirow{2}{*}{$\begin{array}{l}\text { Physicians } \\
\text { characteristics }\end{array}$} & & \multirow[b]{2}{*}{$\begin{array}{l}\text { Do not refer to a } \\
\text { dietitian or } \\
\text { endocrinologist } \\
\text { (\%) }\end{array}$} & \multicolumn{2}{|c|}{ Multivariate analysis } & \multirow[b]{2}{*}{$\begin{array}{l}p- \\
\text { value }\end{array}$} \\
\hline & & & $\begin{array}{l}\text { Relative } \\
\text { Risk }\end{array}$ & $\begin{array}{l}95 \% \\
\text { confidence } \\
\text { interval }\end{array}$ & \\
\hline \multirow[t]{3}{*}{ Gender } & & & & & 0.0296 \\
\hline & Female & $66(42.3)$ & 1.00 & & \\
\hline & Male & $53(47.7)$ & 1.35 & $1.03-1.76$ & \\
\hline \multirow[t]{3}{*}{ Age (years) } & & & & & 0.0005 \\
\hline & $30-49$ & $105(49.3)$ & 1.00 & & \\
\hline & $\geq 50$ & $14(25.9)$ & 0.46 & $0.28-0.75$ & \\
\hline \multirow[t]{4}{*}{ Specialty } & & & & & $<.0001$ \\
\hline & $\begin{array}{l}\text { Clinical } \\
\text { oncologist }\end{array}$ & $46(32.4)$ & 1.00 & & \\
\hline & Breast surgeon & $68(58.6)$ & 1.99 & $1.50-2.64$ & \\
\hline & $\begin{array}{l}\text { Radiation } \\
\text { oncologist }\end{array}$ & $5(55.6)$ & 1.70 & $0.88-3.30$ & \\
\hline \multirow[t]{3}{*}{ Clinical practice } & & & & & 0.0012 \\
\hline & $\begin{array}{l}\text { Exclusively / } \\
\text { Greater mostly } \\
\text { private service }\end{array}$ & $74(38.7)$ & 1.00 & & \\
\hline & $\begin{array}{l}\text { Exclusively / } \\
\text { Greater mostly } \\
\text { public service }\end{array}$ & $45(59.2)$ & 1.53 & $1.20-1.96$ & \\
\hline \multirow{3}{*}{$\begin{array}{l}\text { Do you treat breast } \\
\text { cancer? }\end{array}$} & & & & & 0.0692 \\
\hline & Yes & $114(43.8)$ & 1.00 & & \\
\hline & No & $5(71.4)$ & 2.38 & $1.33-4.26$ & \\
\hline \multirow{3}{*}{$\begin{array}{l}\text { Do you personally } \\
\text { follow the } \\
\text { recommendations of } \\
\text { eating habits? }\end{array}$} & & & & & 0.4311 \\
\hline & Yes & $100(43.9)$ & 1.00 & & \\
\hline & No & 19 (48.7) & 1.15 & $0.83-1.60$ & \\
\hline
\end{tabular}




\begin{tabular}{llll} 
Yes & $103(43.6)$ & 1.00 & \\
\hline No & $16(51.6)$ & 1.18 & $0.82-1.71$
\end{tabular}

\section{Do you consume} alcohol?

\begin{tabular}{llll} 
Yes & $101(47.6)$ & 1.00 & \\
\hline No & $18(32.7)$ & 0.75 & $0.50-1.11$
\end{tabular}

\section{Do you smoke?}

0.1488

\begin{tabular}{|llllll|}
\hline & Yes & $2(25.0)$ & 1.00 & & \\
\hline & No & $117(45.2)$ & 1.84 & $0.69-4.94$ & \\
\hline $\begin{array}{l}\text { Average sleep time per } \\
\text { day }\end{array}$ & & & & & 0.4283 \\
& $<5 h$ & $6(54.5)$ & 1.00 & & \\
\hline & Between $5-7 \mathrm{~h}$ & $16(36.4)$ & 0.59 & $0.30-1.17$ & \\
\hline What is your BMI? & $>7 \mathrm{~h}$ & $97(45.7)$ & 0.66 & $0.38-1.17$ & \\
\hline & $<25$ & & & & 0.1031 \\
\hline & $\geq 25$ & $83(47.7)$ & 1.00 & & \\
\hline
\end{tabular}

\section{Discussion}

Adherence to healthy lifestyle guidelines is important for BC patients to reduce their risk of recurrence, to improve quality of life and overall survival.(3) Increasing adherence of breast cancer survivors to a healthier lifestyle, including a balanced diet and regular physical activity, can increase their survival by up to $40 \%$. (9) Physicians have a critical role in assisting BC patients to adapt healthy lifestyle. In our study we found that $85.4 \%$ of physicians followed the guidelines on diet most of the time and $88.4 \%$ practice physical activity, while $84.3 \%$ of them advised their BC patients on the importance of lifestyle modification. Our results are aligned with previous studies which have shown that, when health professionals engage in healthy behaviors, they are more likely to provide preventive counseling to their patients. (14-17)

When we evaluated the correlations, we found that physicians who practiced physical activity regularly had more chance to advise lifestyle changes for BC patients. A similar correlation was previously demonstrated in a survey with North American physicians which showed that physicians who practiced 
aerobic exercise regularly were more likely to advise their patients on the benefits of exercise (OR 5.72; $95 \% \mathrm{Cl} 2.41-13.54 ; \mathrm{p}<0.0005)$. (14) However, the rates of advising physical activity remains suboptimal. Studies have demonstrated that only $28 \%$ of patients receive any advice about physical activity, and $40 \%$ of them receive some assistance in planning an exercise routine. Physicians mention the need for exercise but do not specify or discuss the types of exercise or their frequency. (18) Stimulating physical activity is essential for cancer survivors, since there is strong evidence that moderate to intense aerobic activity $3 x$ per week combined with resistance exercise training not only can reduce anxiety, depressive symptoms, and fatigue, but also can improve overall quality of life. $(19,20)$

Regarding the importance of weight management, it is well known that women with $\mathrm{BC}$ who gain weight during or after treatment have been shown to have a worse prognosis, $(5,21)$ especially those who gained more than $10 \%$ weight after diagnosis (HR 2.67; 95\%Cl, 1.37-5.05). (21) In addition, breast cancer survivors who had a diet rich in saturated fats, especially dairy products, had an increase in mortality. (22) (23) In our study, we found that only $45.3 \%$ of physicians did some type of obesity management and $53.4 \%$ of the overweight or obese patients were referred to a dietitian and/or endocrinologist. Being a breast surgeon or radiation oncologist were factors associated with not performing obesity treatment and management. Additionally, physicians with clinical practice exclusively or mostly in the public health care system had an increased risk of not referring overweight and obese patients to a dietitian or endocrinologist. These findings might be explained by an overload both in terms of the physician's time and the back log of specialized consultations in the public health care system. Conversely, physicians older than 49 years had lower risk of not referring overweight or obese patients to a dietitian and/or endocrinologist. Other physician habits also seemed to correlate with advice and prescriptions; however, these findings were not statistically significant, possibly because of the sample size.

Motivating cancer patients to change their diet, exercise and adopt healthy lifestyle has always been challenging, since patients may feel it more difficult to exercise after diagnosis and treatment. In the past, clinicians used to advise cancer patients to rest and to avoid physical activity, but research done in the 1990s and 2000s has questioned this concept, leading to a change in practice guidelines. (24) Exercise is not only safe and possible during cancer treatment, but it can improve physical function and quality of life. Currently, the recommendation is that physicians, including oncologists, counsel cancer survivors to adopt healthy lifestyles (25).

Despite the mentioned benefits and recommendations of healthy lifestyle for $\mathrm{BC}$ patients, there are several barriers to medical advice on healthy lifestyle, including: insufficient training and lack of confidence to advise healthy diet and exercise. (26) An online questionnaire that assessed 971 oncology providers practice patterns and perceptions of obesity and weight management during and after cancer treatment showed that although the majority reported advising patients to maintain a healthy weight, increase physical activity, and eat healthy, only $42 \%$ of them refer patients to dietitian. The main barriers identified were lack of education, lack of time, lack of adequate programs to make referrals, and resistance of patients to change lifestyle. (27) These findings reinforce that training related to lifestyle modification should be incorporated into the medical school curriculum, fellowship programs and 
continuing medical education to enhance physicians' knowledge and competence, including lifestyle management and behavioral change skills.

The present study has limitations that need to be addressed. First, the self-report nature (thus information about socially undesirable behaviors such as smoking, and alcohol use may be underreported). Second, the population studied includes only LACOG and SBOC members, which already selects professionals with an academic profile and may impact the generalization of the information obtained. Third, respondents may represent a population that is specifically interested in the topic.

There is extremely limited information on Latin American physician lifestyle and its impact on the prescription of healthy habits to BC patients. Our study results may increase awareness and help design interventions to improve health professionals' own habits and health-promoting behaviors.

In conclusion, physicians treating BC patients have a healthy lifestyle. Physicians who practice physical activity regularly or that are older than 50 years had more chance to advise lifestyle modification. Only half of BC patients' physicians treat obesity or refer these patients to specialist which in this case may impact BC patient's outcome. Thus, strategies to engage physicians in healthy habits, as well as educational initiatives, should be stimulated for physicians treating patients with breast cancer.

\section{Abbreviations}

BC: Breast cancer

Cl: Confidence interval

HR: Hazard ratio

LACOG: Latin American Cooperative Oncology Group

OS: Overall survival

RR: Risk relative

SBOC: Brazilian Society of Clinical Oncology

WHO: World Health Organization

\section{Declarations}

\section{Funding:}

There was no funding source for this survey.

Conflicts of interest/Competing interests: 
The authors declare that there is no conflict of interest regarding the publication of this article

Code availability:

The datasets analyzed e Code used for this survey are available from the corresponding author on reasonable request.

Authors' contributions:

Concept and design: RC, EM, PRNN, GW

Statistical analysis: RGJ

Analysis of data and interpretation: RC, EM, PRNN, TFR, FZ, RGJ, GW

First draft of the manuscript: RC, EM, PRNN, TFR, FZ, RGJ, GW

All authors contributed to the content of the report and reviewed further drafts. All authors reviewed and approved the final report before submission. The authors take full responsibility for the scope, direction, and content of the report.

Ethics approval:

the survey was approved by Institutional Review Board of Núcleo de Oncologia da Bahia Consent to participate:

Not applicable

Consent for publication:

Not applicable

Disclosure:

The authors declare that there is no conflict of interest regarding the publication of this article

\section{References}

1. Bray F, Ferlay J, Soerjomataram I, Siegel RL, Torre LA, Jemal A. Global cancer statistics 2018: GLOBOCAN estimates of incidence and mortality worldwide for 36 cancers in 185 countries. CA Cancer J Clin [Internet]. 2018;68(6):394-424. Available from: https://doi.org/10.3322/caac.21492

2. O'Shaughnessy J. Extending survival with chemotherapy in metastatic breast cancer. Oncologist. 2005;10 Suppl 3:20-9. 
3. Hamer J, Warner E. Lifestyle modifications for patients with breast cancer to improve prognosis and optimize overall health. C Can Med Assoc J = J I'Association medicale Can. 2017 Feb;189(7):E26874.

4. Organization WH. WHO report on cancer: setting priorities, investing wisely and providing care for all [Internet]. Geneva PP - Geneva: World Health Organization; Available from: https://apps.who.int/iris/handle/10665/330745

5. Ghose A, Kundu R, Toumeh A, Hornbeck C, Mohamed I. A review of obesity, insulin resistance, and the role of exercise in breast cancer patients. Nutr Cancer. 2015;67(2):197-202.

6. Chlebowski RT, Blackburn GL, Thomson CA, Nixon DW, Shapiro A, Hoy MK, et al. Dietary fat reduction and breast cancer outcome: interim efficacy results from the Women's Intervention Nutrition Study. J Natl Cancer Inst. 2006 Dec;98(24):1767-76.

7. Chlebowski RT, Aragaki AK, Anderson GL, Simon MS, Manson JE, Neuhouser ML, et al. Association of Low-Fat Dietary Pattern With Breast Cancer Overall Survival: A Secondary Analysis of the Women's Health Initiative Randomized Clinical Trial. JAMA Oncol. 2018 Oct;4(10):e181212.

8. WHO. Global recommendations on physical activity for health. Geneva: World Health Organization. 2010.

9. Lahart IM, Metsios GS, Nevill AM, Carmichael AR. Physical activity, risk of death and recurrence in breast cancer survivors: A systematic review and meta-analysis of epidemiological studies. Acta Oncol. 2015 May;54(5):635-54.

10. Ibrahim EM, Al-Homaidh A. Physical activity and survival after breast cancer diagnosis: metaanalysis of published studies. Med Oncol. 2011 Sep;28(3):753-65.

11. Oberg EB, Frank E. Physicians' health practices strongly influence patient health practices. J R Coll Physicians Edinb. 2009 Dec;39(4):290-1.

12. Vickers KS, Kircher KJ, Smith MD, Petersen LR, Rasmussen NH. Health behavior counseling in primary care: provider-reported rate and confidence. Fam Med. 2007;39(10):730-5.

13. Frank E. STUDENTJAMA. Physician health and patient care. JAMA. 2004 Feb;291(5):637.

14. Abramson S, Stein J, Schaufele M, Frates E, Rogan S. Personal exercise habits and counseling practices of primary care physicians: a national survey. Clin J Sport Med Off J Can Acad Sport Med. 2000 Jan;10(1):40-8.

15. Lobelo F, Duperly J, Frank E. Physical activity habits of doctors and medical students influence their counselling practices. Br J Sports Med. 2009 Feb;43(2):89-92.

16. Frank E, Dresner $Y$, Shani M, Vinker S. The association between physicians' and patients' preventive health practices. C Can Med Assoc J = J I'Association medicale Can. 2013 May;185(8):649-53.

17. Frank E, Wright EH, Serdula MK, Elon LK, Baldwin G. Personal and professional nutrition-related practices of US female physicians. Am J Clin Nutr. 2002 Feb;75(2):326-32.

18. Glasgow RE, Eakin EG, Fisher EB, Bacak SJ, Brownson RC. Physician advice and support for physical activity: results from a national survey. Am J Prev Med. 2001 Oct;21(3):189-96. 
19. Courneya KS, Mackey JR, Bell GJ, Jones LW, Field CJ, Fairey AS. Randomized controlled trial of exercise training in postmenopausal breast cancer survivors: cardiopulmonary and quality of life outcomes. J Clin Oncol Off J Am Soc Clin Oncol. 2003 May;21(9):1660-8.

20. Cramp F, Byron-Daniel J. Exercise for the management of cancer-related fatigue in adults. Cochrane database Syst Rev. 2012 Nov;11:CD006145.

21. Bradshaw PT, Ibrahim JG, Stevens J, Cleveland R, Abrahamson PE, Satia JA, et al. Postdiagnosis change in bodyweight and survival after breast cancer diagnosis. Epidemiology. 2012 Mar;23(2):320-7.

22. Makarem N, Chandran U, Bandera E V, Parekh N. Dietary fat in breast cancer survival. Annu Rev Nutr. 2013;33:319-48.

23. Kroenke CH, Kwan ML, Sweeney C, Castillo A, Caan BJ. High- and low-fat dairy intake, recurrence, and mortality after breast cancer diagnosis. J Natl Cancer Inst. 2013 May;105(9):616-23.

24. Schrack JA, Gresham G, Wanigatunga AA. Understanding physical activity in cancer patients and survivors: new methodology, new challenges, and new opportunities. Cold Spring Harb Mol case Stud [Internet]. 2017 Jul 5;3(4):a001933. Available from: https://pubmed.ncbi.nlm.nih.gov/28679694

25. Runowicz CD, Leach CR, Henry NL, Henry KS, Mackey HT, Cowens-Alvarado RL, et al. American Cancer Society/American Society of Clinical Oncology Breast Cancer Survivorship Care Guideline. J Clin Oncol [Internet]. 2015 Dec 7;34(6):611-35. Available from: https://doi.org/10.1200/JC0.2015.64.3809

26. Stump TK, Robinson JK, Yanez B, Penedo F, Ezeofor A, Kircher S, et al. Physicians' perspectives on medication adherence and health promotion among cancer survivors. Cancer. 2019 Dec;125(23):4319-28.

27. Ligibel JA, Jones LW, Brewster AM, Clinton SK, Korde LA, Oeffinger KC, et al. Oncologists' Attitudes and Practice of Addressing Diet, Physical Activity, and Weight Management With Patients With Cancer: Findings of an ASCO Survey of the Oncology Workforce. J Oncol Pract. 2019 Jun;15(6):e520-8.

\section{Supplementary Files}

This is a list of supplementary files associated with this preprint. Click to download.

- SupplementaryMaterialTableS1.docx 